\title{
Discussion: Application to panels: key failings or myths at interview
}

A K Hughes BSC, PhD, DMS, CEng, FICE, FCIWEM, MIMgt

I refer to Peters (2019) article.

I would have thought that the WRE1 comment could have been a little more informative. The course is for more than 'baseline', whatever that means. I introduces the basics of dam design, instrumentation, failure modes, the various legislative frameworks, and focusses in the first three days of a week long course on looking at the skills and attributes needed by a Supervising Engineer, then visiting two sites, preparing two dummy statements and reporting back to a Supervising Engineer.

I would suggest it a little more than 'baseline'!

\section{REFERENCE}

Peters A (2019) Application to panels: key failings or myths at interview. Dams and Reservoirs 29(2): 55-58, https://doi.org/ 10.1680/jdare.18.00051. 